\title{
Transition from three-port vats pulmonary resections to uniportal vats pulmonary resections: a single center experience
}

\author{
JH Chung ${ }^{*}$, YS Choi \\ From 23rd World Congress of the World Society of Cardio-Thoracic Surgeons \\ Split, Croatia. 12-15 September 2013
}

\section{Background}

Although standard VATS approach is mostly performed through three or four incisions, recently uniportal VATS pulmonary resections have been reported to be a feasible and promising procedure. We report our initial experience with uniportal VATS.

\section{Methods}

Data were retrospectively collected on patients who underwent uniportal VATS pulmonary resections in Samsung Medical Center between April 2013 and June 2013. Age, sex, diagnosis, anatomic resection, surgical technique and duration, incision size, complications, chest tube duration, length of hospital stay, reoperation, and mortality rate were examined.

\section{Results}

10 major pulmonary resections (9 lobectomies and 1 segmentectomy) and 28 wedge resections (7 pneumothorax, 16 lung cancers, 2 interstitial lung disease, 1 hamartoma, 1 tuberculoma, 1 fibrous tumor of pleura) were performed by a single surgeon. With wedge resections, mean postoperative hospital length of stay, chest tube duration, and operative duration were 3 days, 2.07 days, and 69 minutes. With major pulmonary resections, mean postoperative hospital length of stay, chest tube duration, and operative duration were 6 days, 4.2 days, and 169 minutes.

There was one conversion to 3-port VATS during wedge resection due to thick pleural adhesion and one conversion to minithoracotomy during right upper lobectomy due to bronchial injury from technical error.

\footnotetext{
* Correspondence: bozof@hanmail.net

Department of Thoracic Surgery, Samsung Medical Center, Seoul, Korea
}

There was no postoperative mortality or reoperation. One postoperative air leakage lasting longer than one week was noted after uniportal VATS right upper lobectomy which was resolved without any additional treatment.

\section{Conclusions}

Although strict indications and some surgical tips might be needed in the initial period, uniportal VATS appears to be a safe and feasible procedure, which could be easily incorporated in diverse fields of thoracoscopic surgery without a long learning curve in established thoracic surgeons.

Published: 11 September 2013

doi:10.1186/1749-8090-8-S1-O241

Cite this article as: Chung and Choi: Transition from three-port vats pulmonary resections to uniportal vats pulmonary resections: a single center experience. Journal of Cardiothoracic Surgery 2013 8(Suppl 1):0241.

Submit your next manuscript to BioMed Central and take full advantage of:

- Convenient online submission

- Thorough peer review

- No space constraints or color figure charges

- Immediate publication on acceptance

- Inclusion in PubMed, CAS, Scopus and Google Scholar

- Research which is freely available for redistribution 